\title{
A IMPORTANCIA DA ORIENTAÇÃO VOCACIONAL OCUPACIONAL PARA A ESCOLHA PROFISSIONAL DO ALUNO ADOLESCENTE
}

\author{
Adriana Araujo dos Santos ${ }^{1}$ \\ Marilene Santos Lima Pereira²
}

\begin{abstract}
RESUMO
Este trabalho traz a luz o tema sobre a Importância da Orientação Vocacional Ocupacional para a escolha profissional do aluno adolescente. O objetivo geral do trabalho é discutir almportância da orientação vocacional ocupacional para os alunos adolescentes,tendo comohipótese que a orientação vocacional ocupacional é importante para a elaboração de suas reflexões, conflitos e dúvidas acerca de seu futuro, para buscar a elaboração de um projeto pessoal que possibilite uma maior consciência de si mesmo e da realidade sócioprofissional. É nesta tensão entre encontrar o seu estilo de vida e a decisão profissional que os alunos se sentem pressionados diante de sua escolha. Este trabalho traz uma revisão da literatura, com análise de artigos, livros, teses e dissertações, com conhecimento teórico adequado, reconstruindo ideias, teorias, polêmicas, aprimorando fundamentos teóricos, que responderam à questão norteadora (problema), ao termino do estudo chegou a conclusão que a hipótese foi confirmada, sendo assim, o objetivo foi alcançado. O resultado foi positivo, mostrando que para esta autora, o termo orientação profissional estaria associado ao esclarecimento sobre as profissões, enquanto a orientação vocacional convocaria o aluno adolescente a ser sujeito de sua própria vida, sendo os dois campos dissociados. Neste contexto, uma intervenção psicológica realizada no processo de escolha profissional (orientação vocacional ocupacional) se torna importante.
\end{abstract}

Palavras-Chave: Escolha Profissional, Orientação Vocacional Ocupacional, Aluno Adolescente.

\begin{abstract}
This work brings the discussion of the theme Importance of Occupational Vocational Guidance to the professional choice of the adolescent student. The general objective of the study is to discuss the importance of occupational vocational guidance for adolescents for their professional choice, the hypothesis is that occupational vocational guidance is important for the adolescent in the elaboration of his reflections, conflicts and doubts about his future, for to seek the elaboration of a personal project that allows a greater awareness of itself and of the socioprofessional reality, allowing the guidance to understand the determinants involved in choosing a profession. It is in this tension between finding your lifestyle and professional decision that teens feel pressured at their choice. This work presents a Literature Review, with analysis of articles, books, theses and dissertations, with adequate theoretical knowledge, reconstructing ideas, theories, controversies, improving theoretical foundations, which answered the guiding question (problem), confirmed the hypothesis and the objective it was achieved. The result was positive, showing that for this author, the term professional orientation would be associated to the clarification about the professions, while the vocational guidance would call the adolescent to be the subject of his own life, the two fields being dissociated. In this context, a psychological intervention performed with the adolescent in the process of professional choice (vocational vocational guidance) becomes important.
\end{abstract}

Keywords: Professional Choice, Occupational Vocational Guidance, Adolescent student.

\footnotetext{
${ }^{1}$ Mestra em Ciências da Educação pela Facultad Interamericana de Ciencias Sociales - FICS, em Assunção-Paraguai. Email: adriaraujos@outlook.com

2 Doutoranda em Ciências da Educação pela Facultad Interamericana de Ciencias Sociales -

FICS, em Assunção-Paraguai. Email: mari.bela92lima@gmail.com
} 


\section{Introdução}

A adolescência é a etapa do desenvolvimento humano em que ocorrem mudanças mais significativas no ser humano, é neste momento que 0 adolescente passa por várias transformações, sendo elas física, psicológica e emocional. $\mathrm{O}$ adolescente vive nesta fase um período de transição, pois quer ser adulto e por outro lado quer continuar sendo crianças.

Neste período, o adolescente também vivencia a crise de identidade, um processo de construção de identidade sexual, ideológica e profissional. Perante tantas transformações em sua vida, o adolescente precisa ainda escolher a profissão, o que gostaria de ser daqui para frente, diante das diversas possibilidades no mundo em constante modificação.

A formação da identidade profissional é uma etapa do desenvolvimento humano que acontece desde a infância, com as identificações que o sujeito faz ao longo de sua história de vida com adultos significativos no desempenho da sua atuação profissional. A maioria dos adolescentes é influenciada pela família, pelos amigos e pela sociedade na escolha de uma carreira profissional. No Brasil escolas privadas de ensino médio oferecem a orientação ocupacional, às vezes sob a forma simplista de uma "Semana das profissões", na qual especialistas de várias áreas falam de suas experiências.

$\mathrm{Na}$ maioria das escolas públicas nem mesmo ciclos desse tipo são comuns e, em geral, os estudantes não têm recursos para buscar orientação individual e especializada. Usualmente, o jovem procura informações por si mesmo, as famílias costumam influenciar na escolha, mas a dúvida é comum, e é um dos ingredientes da alta taxa de evasão de cursos.

A questão norteadora (problema) desta pesquisa é: Como a Orientação Vocacional Ocupacional pode ser importante no processo de escolha profissional do aluno adolescente?

O objetivo desta pesquisa é discutir a Importância da orientação vocacional ocupacional para os alunos adolescentes na sua escolha profissional. A relevância dessa pesquisa se constitui em ser um tema da atualidade que traz muita angústia tanto para os adolescentes, no momento da escolha profissional e da construção do seu projeto de vida para o futuro. 
Este estudo, de acordo com a questão formulada, é uma pesquisa teórica ou bibliográfica que é orientada no sentido de reconstruir teorias, conceitos, condições explicativas da realidade, ideias, polêmicas e discussões pertinentes, tendo em vista, em termos imediatos, aprimorar fundamentos teóricos. Com relação aos procedimentos, a metodologia, a coleta de dados foi realizada através de uma ampla revisão da literatura. Posteriormente a esta coleta procedeu-se uma análise que buscou extrair considerações analíticas.

\section{A Importância da Orientação Vocacional Ocupacional}

Escolher uma profissão na adolescência é entender que está ocorrendo o desenvolvimento da personalidade e sua integração. Espera-se que no final da fase da adolescência, uma identidade profissional esteja estabelecida, pois tal construção e consolidação desta identidade são um dos fatos que marcam a passagem do jovem pela adolescência.

Os adolescentes sofrem com ansiedade no momento de uma escolha vocacional. Para Sigmund Freud (1926, p. 152), a ansiedade é "uma reação a uma situação de perigo". A ansiedade é uma reação normal diante de situações que podem provocar medo, dúvida ou expectativa. Sendo considerada normal quando esta se manifesta nas horas que antecedem uma entrevista de emprego, a publicação dos aprovados num concurso, o nascimento de um filho. Nesses casos, a ansiedade funciona como um sinal que prepara a pessoa para enfrentar o desafio e, mesmo que ele não seja superado, favorece sua adaptação às novas condições de vida. Também é estado frequente nos indivíduos quando este encontra-se diante da percepção de perigo real. A reação a este perigo seria o reflexo de fuga.

\footnotetext{
A ansiedade é, em primeiro lugar, algo que se sente. Como um sentimento, a ansiedade tem um caráter muito acentuado de desprazer. (...) a ansiedade se faz acompanhar de sensações físicas mais ou menos definidas que podem ser referidas a órgãos específicos do corpo (FREUD, 1926, p. 155).
}

Neste contexto de ansiedade, conflitos e lutos, os adolescentes são influenciados por diversos fatores internos e externos. A identidade ocupacional forma uma parte importante no processo do senso de identidade, constituindose numa das principais tarefas a serem desenvolvidas na adolescência, onde a escolha vocacional faz parte da definição desta identidade ocupacional. 
Para Bohoslavsky (2007, p. 30), a identidade ocupacional é "como um momento de um processo submetido às mesmas leis e dificuldades daquele que conduz à conquista da identidade pessoal". Apesar da identidade ocupacional se desenvolver como um aspecto da identidade pessoal, pode-se assim dizer que são dois processos que caminham juntos em determinado momento de transição, a adolescência da vida do indivíduo.

De acordo com Levenfus (1997), a escolha configura-se como uma despedida, um luto. Os lutos a serem elaborados são os lutos básicos da adolescência que emergem face à escolha profissional. Os seguintes lutos advêm das perdas por escolhas na adolescência: o luto pela perda dos pais da infância, pela perda das escolhas profissionais realizadas, pelo corpo adolescente, pelas identificações profissionais que abandona, pelo papel e pela identidade adolescente.

A escolha profissional leva o adolescente à construção de sua própria identidade, porém isto só poderá ocorrer se este indivíduo tiver realizado o processo de separação-individuação.

Segundo Levenfus (1997), caso isto não tenha acorrido, o adolescente estará mais confuso e indeciso na escolha vocacional do que normalmente encontra-se neste período de escolha. A individuação na adolescência deve ser o último passo para uma construção de identidade do adolescente, porém ele possui ainda uma identidade precária. Mas quando ocorre a consolidação da identidade do jovem, este já consegue apreciar seus pais em conteúdos mais realistas. Ou seja, as imposições paternas podem ser seguidas sob a visão de que foram incorporadas, por identificação.

Para Levenfuset al (2002), a maioria dos estudantes do ensino médio afirma que esta é a melhor fase para que ocorra a escolha profissional. Mas para ocorrer uma escolha ajustada é necessário que o indivíduo tenha: capacidade de se adequar, de interpretar e juízo da realidade, de discriminação, de hierarquização dos objetos e, também ser capaz de esclarecer a ambiguidade e tolerar a ambivalência nas relações de objeto (LEVENFUS ET AL., 2002).

De acordo com esses autores, se o adolescente fizer uma escolha ajustada, ele conseguirá unir seus desejos e as oportunidades que virão, 
gerando assim satisfação pessoal, condições de crescimento, entre outros fatores que alicerçam acarreira escolhida.

Segundo Levenfus (1997), o ato de escolher envolve não só aspectos cognitivos, ou seja, a capacidade de informar-se sobre as diversas profissões existentes, mas também aspectos afetivos os quais poderão dificultar a escolha de uma profissão.

Esta autora destaca alguns aspectos que dificultam o ato de escolher, sendo eles: quando um jovem é dotado de muitas aptidões; quando um jovem tem uma dificuldade pessoal frente à capacidade de descriminação e diferenciação tanto das profissões quanto de seus próprios aspectos, e a forma como um jovem agrupa as carreiras por meio de critérios que busca escolher.Existem situações, nas quais o adolescente ainda não conseguiu estabelecer vínculos diferenciais com os objetos (LEVENFUS 1997, p. 184).

Em todo projeto de vida não pode ser elaborado somente pela influência do ambiente: família, amigos, escola e da realidade sócio-profissional, mas deve possibilitar também a expressão do desejo, do princípio do prazer (SOARES LUCCHIARI, 1997). Deste modo, observa-se que o projeto de futuro profissional contém representações do próprio sujeito, imagens, desejos e objetos de identificação, a expectativa, consciente e inconsciente, que o adolescente constrói de seu futuro enquanto profissional.

Logo, é importante que a orientação vocacional, estude o futuro projeto profissional do adolescente e sua relação com os ideais, possibilitando, uma escuta das descrições que o jovem faz das profissões e das pessoas que lhe são significativas, bem como do estilo de vida que imagina ter no futuro, de como gostaria de ser no desempenho de sua profissão, de como pensa seu ambiente de trabalho, e de como imagina que se sentiria realizando a atividade desejada.

A identidade profissional é compreendida como um desdobramento da identidade pessoal, referindo-se ao ciclo de desenvolvimento da adolescência como um marco vital para o estudo da identidade ocupacional (LISBOA, 1997). Neste momento o jovem é convocado a tomar uma importante decisão sobre o que fazer profissionalmente, sendo instigado a pensar sobre seu futuro e consequentemente o mundo do trabalho, sendo este tema, na maioria das vezes, introduzido pela família e pela escola. 
A capacidade que o sujeito tem de favorecer a expressão de seus desejos, somados com a capacidade de poder controlá-los, quando necessário, dá a ele condições de realizar uma escolha amadurecida e que seja mais aproximada de seus reais interesses. De acordo com esse enfoque, o indivíduo vai escolher as atividades profissionais que possam condizer com seus desejos mais profundos, construídos por ocasião da estruturação da personalidade.

Com o advento da orientação vocacional clínica, verifica-se uma maior tentativa de compreensão do momento da decisão, utilizando o método clínico, distanciando-se da visão fragmentada do sujeito que escolhe e aproximando-se da relação sujeito e objeto no processo de decisão.

Soares (2002) ressalta que a orientação vocacional deverá aprofundar as dimensões do vocacional (vocare) e do ocupacional (profissão), as questões da identidade vocacional e profissional, no sentido proposto por Bohoslavsky (1997), isto é, respondendo aos "para que" e "porquês" da escolha de determinada profissão.

Em contrapartida os termos ocupacional e profissional relacionam-se ao fazer que necessita então de objetos, ferramentas, símbolos, técnicas, estratégias, para efetivar o vocacional. Sendo assim, é necessário que se integre o vocacional e o ocupacional, ou seja, o ser e o fazer para a realização da escolha de uma profissão.

A complexidade do funcionamento da psique humana e o que ela demanda interna e externamente durante $o$ ato de uma escolha, devendo incitar constantemente o orientador ocupacional a desenvolver novos olhares e perspectivas, evitando acomodar-se no fazer sempre conhecido e convencionado (TORRES, 2001). Este novo fazer, a autora denomina de orientação profissional clínica, o que seria uma modalidade de trabalho de nível terapêutico, embasada na abordagem psicanalítica, possibilitando uma reavaliação e uma reorganização de conteúdo interno e externo relativos ao orientando. Para esta autora, durante o desenvolvimento do trabalho, deve "favorecer a elaboração de materiais conscientes e também de nível inconsciente, promovendo uma maior aproximação da pessoa com os seus interesses e desejos" (TORRES, 2001, p.127).

O termo orientação profissional é associado a trabalhos que se limitem apenas a informar e a orientar a respeito das profissões e mercado de trabalho, 
aplicando técnicas de aprendizagem e testes psicológicos, no entanto, sem enfatizar as questões intrapsíquicas do orientando (LEVENFUS, 1997). O termo orientação vocacional ou orientação vocacional ocupacional se refere a um processo mais abrangente, que engloba não somente a informação sobre profissões, mas uma busca de conhecimento a respeito de si mesmo, de características pessoais, familiares e sociais do orientando, promovendo o encontro das afinidades do mesmo com aquilo que pode vir a realizar em forma de trabalho, ou seja, objetiva a busca de uma identidade profissional.

Para esta autora, o termo orientação profissional estaria associado ao esclarecimento sobre as profissões, sendo o sujeito apenas alguém que deveria ser orientado, ou seja, um indivíduo que se encontra sem condições de orientar-se por si mesmo, enquanto a orientação vocacional convocaria o adolescente a ser sujeito de sua própria vida, sendo os dois campos dissociados.

$\mathrm{Na}$ orientação vocacional, numa proposta de escuta, fundamentada nos aportes psicanalíticos, a vocação não seria algo que nasce, mas sim algo que faz-se, constrói-se subjetiva e historicamente em interação com os outros, segundo as oportunidades familiares e as disposições pessoais.

\footnotetext{
Elaborar um projeto vocacional/ ocupacional coloca a descoberto a problemática do sujeito e suas disposições psicopatológicas, pois condensa toda a história prévia desta pessoa e, ao mesmo tempo, antecipa seu futuro (MÜLLER, 1988, p.12).
}

Deste modo, deve-se entender que a prática em orientação vocacional deve ser uma tarefa não apenas limitada ao território da clínica, mas também ao espaço escolar. Isto ao fato de que tenha o objetivo de acompanhar o aluno na elaboração de suas reflexões, conflitos e dúvidas acerca de seu futuro, para buscar a elaboração de um projeto pessoal que possibilite uma maior consciência de si mesmo e da realidade sócio-profissional, permitindo ao orientando compreender os determinantes envolvidos na escolha de uma profissão, preparando-se então para desempenhá-la.

\section{Considerações}

A proposta de uma orientação vocacional que focalize a escuta do sujeito, busca favorecer que o aluno considere primeiramente a construção de si mesmo, antes da escolha profissional, visto que é a partir da compreensão 
acerca de quem se é e aonde se deseja chegar que se depreende o que se quer fazer, ou seja, o que escolher para desempenhar profissionalmente.

Diante disso, percebe-se que a prática de orientação vocacional vem contribuir, implicando grande disponibilidade do orientador em compreender 0 que constitui a subjetividade do orientando, sem a necessidade de ensinar, convencer, ou saber previamente sobre o outro, pois sabe-se que cada personalidade possui características distintivas e peculiares que só o próprio adolescente poderá revelar para que o orientador vocacional possa fazer a leitura destes significados.

\section{Referencias}

FREUD, S. Inibições, sintomas e angústia. In: Obras psicológicas completas. Edição Standart brasileira, vol. XX. Rio de Janeiro: Imago, 1974.

BOHOSLAVSKY, R. Orientação vocacional: a estratégia clínica. 12ª . ed., São Paulo: Martins Fontes, 2007.

LEVENFUS, R.S. Os lutos pela escolha profissional. In: R. S. Levenfus, D. H. Soares-Lucchiari, I. C. Silva, M. D. Lisboa, M. C. Lassance\& M. Knobel (Orgs.), Psicodinâmica da Escolha Profissional. Porto Alegre: Artes Médicas, 1997. Orientação Vocacional Ocupacional. IN:

LEVENFUS, Rosane Schotgues; SOARES, Dulce Helena Penna e Cols (et al.).Orientação Vocacional Ocupacional. 1a. edição, Porto Alegre: Artemed, 2002.

LISBOA, M. D. Ser quando crescer... A formação da identidade ocupacional. In: LEVENFUS, R. S. Psicodinâmica da escolha profissional. Porto Alegre: Artes Médicas, 1997.

MÜLLER, M. Orientação vocacional: contribuições clínicas e educacionais. Porto Alegre: Artes Médicas, 1988

SOARES LUCCHIARI, D.H.P. O ideal de Ego e o projeto de futuro profissional dos adolescentes. In: LEVENFUS, R.S. Psicodinâmica da escolha profissional. Porto Alegre: Artes Médicas, 1997.

SOARES, M. C. A escolha profissional: do jovem ao adulto. São Paulo: Summus, 2002.

TORRES, M.L.C. Orientação profissional clínica: uma interlocução com conceitos psicanalíticos. Belo Horizonte: Autêntica, 2001. 